\title{
In Memory of Sergey G. Psakhie
}

\author{
Evgeny V. Shilko, Valentin L. Popov, Olga S. Vasiljeva, \\ and Georg-Peter Ostermeyer
}

\section{Scientific Biography of Professor Sergey Grigorievich Psakhie}

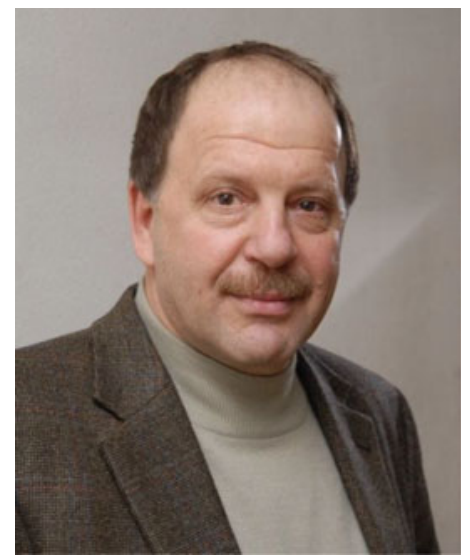

\section{E. V. Shilko}

Institute of Strength Physics, Materials Science SB RAS, 634055 Tomsk, Russia

\section{L. Popov (凶)}

Technische Universität Berlin, 10623 Berlin, Germany

e-mail:v.popov@tu-berlin.de

O. S. Vasiljeva

Jozef Stefan Institute, Ljubljana 1000, Slovenia

G.-P. Ostermeyer

Technische Universität Braunschweig, 38106 Brunswick, Germany 
Sergey G. Psakhie was born on March 2, 1952 in Tomsk (the main city of the Tomsk region in Siberia, USSR) in a family of school teachers Grigory A. Psakhie and Nadezhda A. Psakhie.

His father, Grigory Abramovich Psakhie, was one of the most famous and respected school teachers in the history of Tomsk Region. He has worked as a physics and astronomy teacher for more than half a century and was a school principal in Tomsk and Tomsk Region for about 40 years. Grigory Abramovich is rightfully called the Innovative Teacher. He was one of the first in the USSR to introduce the most advanced system of teaching physics and astronomy at that time, the Shatalov system, and has introduced a large number of other innovations in the school education system in the Tomsk Region. For many years of fruitful educational and enlightenment activities, Grigory Psakhie was awarded numerous orders, medals, and diplomas. The most valuable for him were the Order of the October Revolution and the Janusz Korczak medal "To a teacher who raised students" (the latter had a cult status among the teachers in the USSR). The Academic Lyceum in Tomsk is named after Grigory Psakhie.

Sergey's mother, Nadezhda Alekseevna Psakhie, devoted her whole life to preschool and primary school education for children. For more than half a century in the profession, Nadezhda Psakhie worked as a kindergarten teacher, head of a kindergarten, primary school teacher and educator. At all places of work, she was considered an exemplary teacher and educator. She was awarded numerous diplomas of the Departments of public education of Tomsk and the Tomsk Region. Grigory and Nadezhda Psakhie lived together for 65 years and were awarded a special certificate from the President of the Russian Federation Vladimir Putin as a family who lived a long, happy life together.

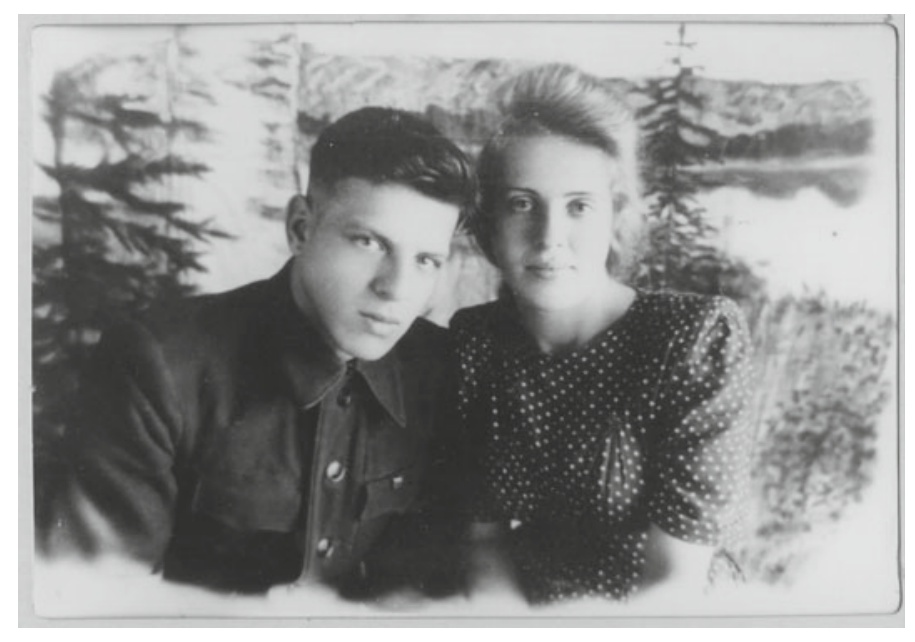

Grigory and Nadezhda Psakhie 
Sergey Psakhie raised and taught two daughters (Olga and Natalia), and son Ivan. Olga (married name Vasiljeva), a Professor of Biochemistry at Jozef Stefan Institute (Slovenia) and an expert in protease biology and oncology, has been working with her father, Sergey Psakhie, on several interdisciplinary projects. Natalia Psakhie is a product manager working at top Silicon Valley (California) tech companies. Ivan Psakhie became a scientist in the molecular biology field.

Sergey Psakhie spent a significant period of his childhood in small villages New Vasyugan, Middle Vasyugan, Kargasok in the north of the Tomsk Region. In some of these villages there were no kindergartens, so Sergey became independent very early and learned to read as early as 3 years old. His parents devoted a lot of time to raising and educating their son, so when Sergey entered the school, the school administration offered to immediately transfer Sergey to the 2nd grade. Already at school, Sergey Psakhie manifested diverse interests, high intelligence, and leadership. He was seriously interested in physics and chess, and at the same time passionately engaged in sports and dances, participated in the performances of the Greek school theater, and wrote talented poems. At the same time, Sergey demonstrated excellent performance in almost all school subjects. In high school, Sergey dreamed of entering a flight school, but in the end, his father-instilled love of physics won.

Upon school graduation, Sergey Psakhie entered the Physics Department of Tomsk State University, from which he graduated in 1976.

In 1976-1979, Sergey Psakhie studied at the graduate school of Tomsk State University (TSU) and carried out scientific research under the guidance of Professor Viktor E. Panin. Viktor Panin became for Sergey not just a scientific supervisor, but a teacher, colleague, and like-minded person for many subsequent decades. In the graduate school of TSU, Sergey Psakhie chose as a scientific specialization a new, and only emerging at that time, direction: computer modeling of processes and phenomena in solids at the atomic level. This direction would later become one of the leading and most successful scientific areas of his future scientific school.

In 1981, Sergey Psakhie successfully defended his thesis for the degree of candidate of physical and mathematical sciences. The theme of his dissertation was "Investigation of the interaction between atoms of alloying elements and vacancies in diluted aluminum-based alloys".

From 1980 to 1984, Sergey Psakhie was a junior researcher at the Institute of Atmospheric Optics of the Siberian Branch of the Academy of Sciences of the USSR (now V. E. Zuev Institute of Atmospheric Optics of the Siberian Branch of the Russian Academy of Sciences) in the Department of solid-state physics and materials science. This department was headed by his scientific adviser Viktor Panin. The best qualities of Sergey Psakhie as a great scientist, such as scientific instinct, understanding of the physical nature of phenomena, the ability to formulate ideas and results, and extraordinary organizational talent, were clearly manifested already during this period.

In 1984, a new research institute was opened in Tomsk - the Institute of Strength Physics and Materials Science of the Siberian Branch of the Academy of Sciences of the USSR (after the collapse of the USSR in 1992 it was renamed to the Institute of Strength Physics and Materials Science of the Siberian Branch of the Russian 
Academy of Sciences, ISPMS SB RAS). Professor Viktor E. Panin was the organizer and first director of the Institute. Together with him and a group of ambitious young scientists, Sergey Psakhie came to the new institute as a senior researcher. The Institute became for Sergey Grigorievich a scientific home for the rest of his life. ISPMS SB RAS is associated with all of his key scientific and career achievements.

In 1985, young ambitious scientist Sergey Psakhie founded a new Laboratory of automation (from 1998, the Laboratory of computer-aided design of materials) and became its head. The scientific formation of his best students have been working in this laboratory. Among them are Dr. Konstantin P. Zolnikov, Dr. Sergey Yu. Korostelev, Dr. Alexey Yu. Smolin, Dr. Andrei I. Dmitriev, Dr. Evgeny V. Shilko, Dr. Andrey V. Dimaki, and many others.

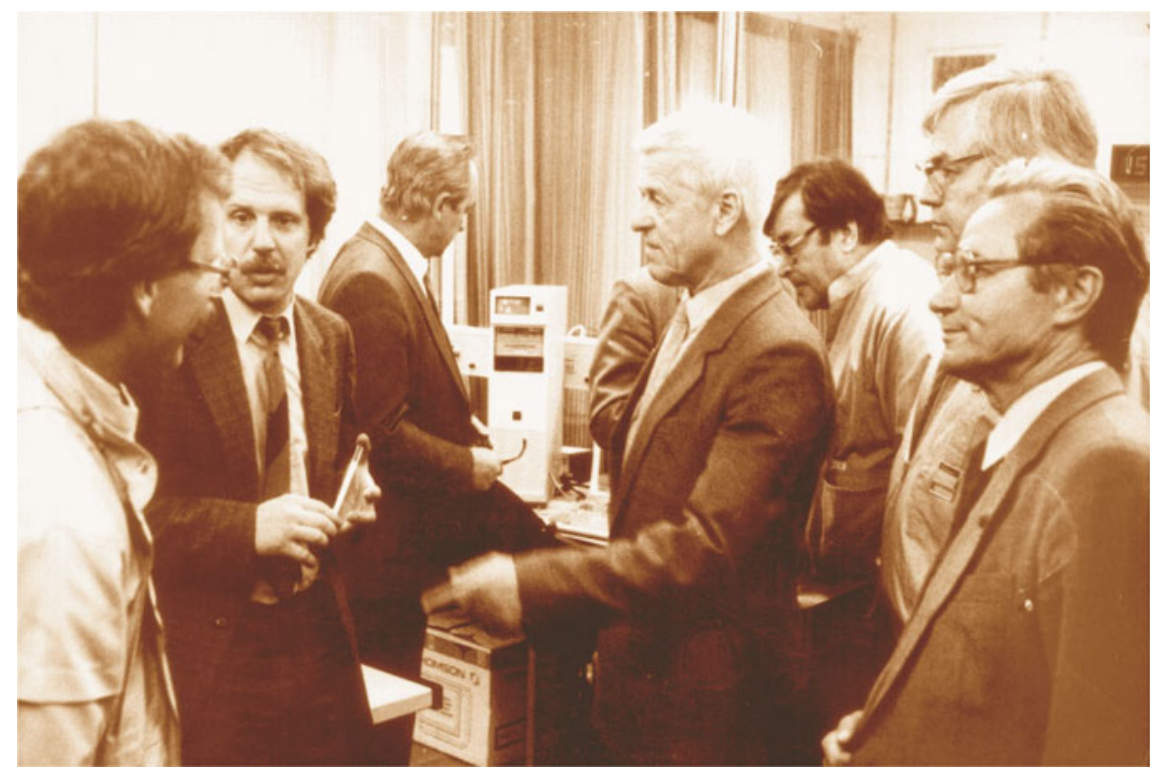

Sergey Psakhie (second from the left) with visitors in the Laboratory of computer-aided design of materials (ca. 1990)

In 1990, Sergey Psakhie successfully defended his dissertation for the degree of Doctor of Physical and Mathematical Sciences at the age of only 38 years and in $\mathbf{1 9 9 1}$ received a Doctor of Science degree. The theme of his dissertation was "Interparticle interactions and nonlinear properties of metals under mechanical stress".

In 1991, Sergey Psakhie took the post of deputy director of the Institute for Research. In this position, he worked until 1993.

In 1994, Sergey Psakhie worked as a visiting professor at North Carolina State University (USA) by the invitation of one of the leading experts in high-rate processes and phenomena in solids, professor Yasuyuki (Yuki) Horie. Work at NCSU significantly changed the worldview of Sergey Psakhie. He fully realized that world-class science can only be successfully developed in close international cooperation. The 
foundations of such cooperation were laid in the American period of his career, and Sergey Psakhie was engaged in its development throughout his subsequent scientific career at ISPMS SB RAS. Close collaboration of Sergey Psakhie and his research team with leading American, European and Chinese scientists enabled the achievement of advanced fundamental and applied results in materials science, and led to international recognition in the form of highly cited papers in high ranked journals, international patents, and scientific contracts with leading European universities and international industrial corporations.

The period of work at the NCSU has become extremely fruitful scientifically. In collaboration with Prof. Yasuyuki Horie, Sergey Psakhie developed a new particle method, namely, movable cellular automaton (MCA) method. This method was originally developed to model mechanically activated chemical reactions in powder mixtures. In fact, it was a hybrid numerical technique, which combines the formalisms of discrete element and cellular automaton methods. Later, the formalism of this method was used to create an advanced implementation of the discrete element method, namely of the method of homogeneously deformable discrete elements.

In the same year 1994, Sergey Psakhie became a member of the New York Academy of Sciences and American Ceramic Society.

From 1995 to 2002, Sergey Psakhie continued his scientific work at ISPMS SB RAS as the head of the Laboratory of computer-aided design of materials in close international cooperation with Prof. Yuki Horie, Prof. Zongguang Wang (Institute of Metal Research CAS, China), Dr. Stanko Blatnik (Jožef Stefan Institute and INOVA d.o.o., Slovenia), Dr. Simon Zavsek (Velenje Coal Mine, Slovenia), Prof. Jože Pezdič (University of Ljubljana), Prof. Georg-Peter Ostermeyer (Technische Universität Berlin, Technische Universität Braunschweig after 2002) and Prof. Valentin L. Popov (Universität Paderborn, Technische Universität Berlin after 2002). Sergey Psakhie was closely related to these scientists not only by joint research, but also by many years of friendship.

Thanks to broad scientific collaboration, several new areas of the Sergey Psakhie scientific school were created during this period, and later became extremely successful:

- development of the formalism of hybrid cellular automaton method (the coupled discrete element-finite difference numerical technique) for the study of gassaturated and fluid-saturated porous materials including coal, sandstone, bone tissues and so on;

- computational study of friction and wear in technical and natural tribounits at different scales using a particle-based approach;

- development of an approach to stress state prognosis and managing the displacement mode and seismic activity of tectonic faults.

The latter approach was co-developed in collaboration with prominent experts in geology and geophysics, Prof. Sergey V. Goldin and Dr. Valery V. Ruzhich. In addition to computational modeling, a key component of these studies was the longterm field research in the dynamics of the segments of tectonic faults and the Lake 
Baikal ice cover, as a model block-structured medium. These studies included longterm monitoring of displacements and seismicity in combination with managing impacts (explosions, vibrations, fluid injection). An important result of these studies, which Sergey Psakhie was rightly proud of, is the Patent of Russian Federation (2006) "A method for controlling the displacement mode in fragments of seismically active tectonic faults".

Sergey Psakhie's colleague, Prof. Valentin L. Popov, has contributed to the development of the three aforementioned scientific areas. He initiated and participated in a large number of joint projects and is the co-author of dozens of joint papers. For the past two decades, Valentin Popov has been Sergey Psakhie's closest friend.

In 2002, Sergey Psakhie took a new decisive step. He became the director of his native Institute (ISPMS SB RAS), succeeding his teacher Academician Viktor E. Panin in this post. Sergey Psakhie made this decision after much deliberation, but subsequently he never regretted it. In his new post, Sergey Psakhie became one of the most famous and successful directors of research institutes in Russia and was able to execute the most ambitious projects in a wide spectrum of scientific fields from materials science and mechanical engineering to geotectonics and biomedicine. Under the leadership of Sergey Psakhie, the ISPMS SB RAS developed rapidly and in 2017 became one of the top research institutes in Russia. It is a first-rank institute and is included in the TOP-10 Russian scientific institutes based on the number of papers published in journals indexed in Web of Science.

Despite working at the research institute, Sergey Psakhie never lost touch with his Alma Mater. Since 1992, he worked as a professor at the Department of Strength and Design of Tomsk State University, and in $\mathbf{2 0 0 5}$ he took the post of head of the Department of High Technology Physics in Mechanical Engineering at Tomsk Polytechnic University. Working both at the research institute and at leading Tomsk universities, Sergey Psakhie made an invaluable contribution to the formation of Tomsk Consortium of Scientific and Educational Organizations enabling integration of Tomsk's educational and scientific systems.

Sergey Psakhie believed that the presence of scientific schools in Russia, including strong Tomsk scientific schools in the fields of theoretical physics, material science, and advanced medicine, is a key advantage of the education system in the Russian Federation. He always considered Tomsk as a place of attraction for the implementation of joint projects with world leading scientific organizations and did a lot to form such projects in the field of materials science. Examples are the project aimed to develop and create the production of advanced wound healing materials "VitaVallis", development of a new multi-beam electron beam technology for high-performance additive production of large-size metal products and structures for key industries in Russian Federation.

The high reputation of Sergey Psakhie as an outstanding organizer of science, determined his active and multifaceted work in the Russian Academy of Sciences.

From January 2004, he combined presiding the ISPMS SB RAS with the post of the Deputy Chairman of the Presidium of the Tomsk Scientific Center of the SB RAS, and from 2006 to 2013 with the post of the Chairman of the Presidium of the Tomsk Scientific Center of the SB RAS. 
Sergey Psakhie was one of the key leaders in the Siberian Branch of the Russian Academy of Sciences, a member of the Presidium of the SB RAS, and Deputy Chairman of the SB RAS contributing to innovative activities and the development of integrated scientific and educational systems in Siberia.

The merited recognition of Sergey Psakhie's high scientific and organizational achievements and scientific reputation led to his election as a Corresponding Member of the Russian Academy of Sciences in $\mathbf{2 0 1 1 . ~}$

Sergey Psakhie has contributed to scientific and organizational work in multiple governmental, municipal, and public organizations. He was a member of the Russian Foundation for Basic Research (RFBR) Council, the Russian National Committee on Theoretical and Applied Mechanics, the Russian National Committee on Tribology, the Interstate Coordination Council on physics of strength and plasticity of materials, the Innovation Council of the Siberian Branch of the Russian Academy of Sciences, multiple coordination councils (including international), the expert committee of the Russian Youth Prize in Nano-industry, the committee for the competition of technological projects, the Tomsk Region Administration, a number of councils for awarding prizes in the Tomsk Region, etc. Over the years, he was a member and co-chair of the organizing committees of many international conferences. He was a member of the editorial boards of three international journals.

For his tenure and achievements in science and the organization of science and education in Russia, Sergey Psakhie was awarded a large number of honors including the title of "Honorary Worker of Science and Technology of the Russian Federation", the medal of the Russian Cosmonautics Federation "For Merits", honorary badges of the SB RAS "Silver Sigma", the medal "Honored Veteran of the SB RAS", and the Order of Friendship, among others.

Despite the high workload of organizational activities, Sergey Psakhie always considered science as his main priority. His great fundamental knowledge, unusually wide erudition, sharp mind, and talent made it possible to achieve great results in various scientific fields. Sergey Psakhie has always actively supported interdisciplinary research conducted at the intersection of different sciences. He saw the prospect of such research in the fact that well-established methods and approaches from one field of science, after some modification, can be efficiently used to obtain breakthrough results in another scientific field. The range of scientific interests of Sergey Psakhie was unusually broad and covered the problems of theoretical research and computer modeling of complex nonlinear processes in technical and natural (biological and geological) materials.

In the last decade, Sergey Psakhie's main research interests have been related to the study of the interactions between hard matter and soft matter in multiphase contrast materials, the study of the features and anomalies of the behavior of solids under mechanical confinement (confined matter), the study of dusty plasma, etc. In particular, implementation of the method of particles (movable cellular automaton method) which he developed in cooperation with Prof. Y. Horie and Prof. V. Popov has been broadly used to solve fundamental and important practical problems in the field of mechanics of solids, fracture mechanics, mechanics and physics of friction and wear, geomechanics and tectonophysics, biomedicine. 
In 2007, he initiated a new scientific direction connected with the theoretical study of plasma-dust crystals. The study of dusty plasma, which is often called the new state of matter, is one of the most promising scientific fields and is developed by collaborations of leading scientific groups around the world.

Since his student years and throughout his scientific career, Sergey Psakhie was actively involved in radiation materials science. His first publications in 1980s were dedicated to this topic. In the 2000s, Sergey Psakhie initiated scientific cooperation with A. A. Bochvar High-Technology Scientific Research Institute for Inorganic Materials (Moscow, Russia), the lead institution for the development of promising structural materials for nuclear power engineering. This extremely fruitful collaboration brought together several leading Russian scientific teams and continues to this day. The results of theoretical studies of Sergey Psakhie's scientific group are unique and important for the development of new materials for nuclear energy, as they shed light on the particular behavior of solids under conditions of high temperatures, pressures and radiation exposure that materials experience in the core of nuclear reactors.

A large place in the professional activity of Sergey Psakhie in recent years has been devoted to scientific and technical cooperation with S.P. Korolev Rocket and Space Corporation Energia (Korolev, Russia). Joint research was aimed at solving specific problems of the rocket and space industry. Among the largest projects implemented was the development of methods and equipment for non-destructive testing of welded joints, the efficient friction stir welding technology, 3D-printing technology of products from polymeric materials under zero-gravity conditions, a new method and equipment for repair and restoration of the surface of glass illuminators damaged as a result of the impact of micrometeorites, and others. A huge role in the implementation of these ambitious projects was played by Alexander G. Chernyavsky, Deputy Chief Designer of S. P. Korolev Rocket and Space Corporation Energia, who became not only a like-minded person, but also a friend of Sergey Psakhie.

Sergey Psakhie initiated and implemented innovative scientific direction related to the physics of nanoscale states of substances. Since the mid-2000s, the ISPMS SB RAS has become one of the leading nanotechnology innovation centers in Russia.

Sergey Psakhie made a great contribution to the study of the biological effect of low-dimensional metal oxide nanostructures and their use for biomedical applications, including the creation of new cancer treatment strategies. Latter studies have been performed in collaboration with his daughter, Prof. Olga Vasiljeva (Jozef Stefan Institute, Slovenia). As such, his publication with multidisciplinary international team "Ferri-liposomes as an MRI-visible drug-delivery system for targeting tumors and their microenvironment" published in Nature Nanotechnology journal, has more than 300 citations. In 2018, Sergey Psakhie and his team received a US patent for the use of such materials to suppress tumor growth (US Patent 10105318 "Low-dimensional structures of organic and/or inorganic substances and use thereof").

The staff of his laboratory and chair treated Sergey Psakhie not just as head and colleague, but as a Teacher and Scientist. Over the years, he mentored 5 Doctors of Sciences and about 20 Candidates of Science (Ph.D.), and published with co-authors 
more than 300 papers. Nowadays, students of his students are successfully defending scientific dissertations.

Sergey Psakhie suddenly passed away on December 22, 2018. On the morning of the day of his death, he met with colleagues and had a long list of planned events. The death of a talented Russian physicist, an outstanding organizer of science, a man who devoted himself to serving and promoting science, shocked the entire Tomsk scientific and educational community and the large number of his Russian and international colleagues and friends.

The loss of such a great scientist and person is shocking and irreparable and will remain so for many more years. Nonetheless, the principles of scientific activities created and applied by Sergey Psakhie, his scientific ideas and undertakings would allow the ISPMS SB RAS, Tomsk and Russian science to successfully develop further. Multiple colleagues, collaborators and mentees of Sergey Psakhie will continue to implement the initiatives of Sergey Psakhie and carry on his innovative work.

The name Sergey G. Psakhie is forever inscribed in gold letters in the history of Russian and international science.

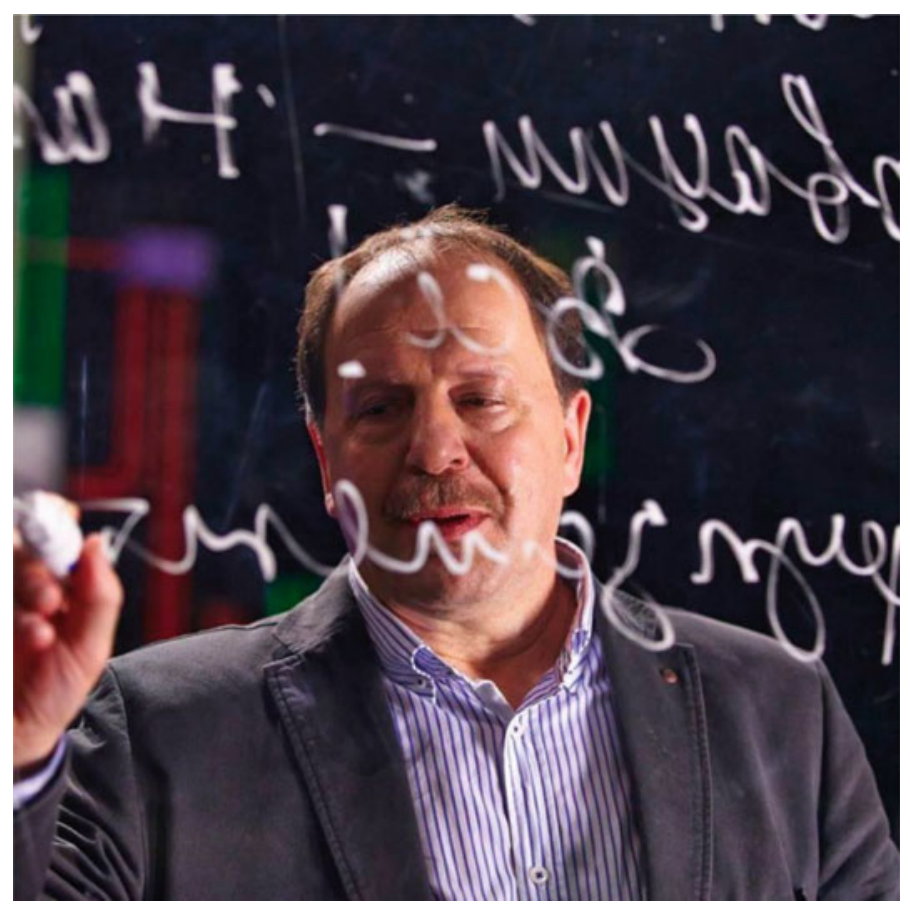

Sergey Grigorievich Psakhie (02.03.1952-22.12.2018) 


\title{
2 Georg-Peter Ostermeyer: Twenty Years of Friendship with Sergey Psakhie
}

\author{
G.-P. Ostermeyer is director of the Institute of Dynamics and Vibrations at the \\ University of Braunschweig, Germany.
}

My wife Ulrike and I first met Professor Psakhie in 1999 in Berlin. There, at the TU Berlin, I established a Collaborative Research Center on friction and invited Prof. Psakhie several times in this context. Besides scientific discussions, we also explored Berlin together and went on extensive hikes in the nature around Berlin. We became friends very soon and he remained our very good friend until the end.

This was also because we were both interested in the philosophy of discrete methods in tribology. We both shared the opinion that mesoscopic simulation methods in particular are essential for tribology. We were in contact all the time and have developed together many ideas. One of these ideas was the simulation of the thermalization process on the mesoscale based on the Shannon theorem. The method of meso particles, which I developed in the late 1990s, and the method of movable cellular automata, developed by Sergei Psakhie, solved this problem in different ways, and the combination of both approaches was a very attractive idea.

It was always a pleasure to have discussions with Sergey Psakhie. With his very broad range of interests and his extensive experience in discrete methods, we would often return to the topic of numerical modeling of multiscale phenomena. Examples of such are material textures in friction processes, which react on slow time scales with surprising motion dynamics, to friction loads, or chemical reactions in the friction boundary layer, which are found on completely different time and size scales. We were fascinated by the idea of treating multiscale effects with different abstract, i.e. scale-independent, methods, whereby the interconnection of these methods alone represents the scale spread. My wife Ulrike, a mathematician, was always fascinated by the mathematical depth of his argumentation even on topics, which were quite far from his fields of research, and Sergey Psakhie enjoyed these inspiring discussions with her.

The last time we met personally was during the International Workshop "Advances in Tribology: Science, Technology and Education" in Karlovy Vary in 2015, organized by Sergey Psakhie together with Valentin Popov and myself. This meeting was like a throwback to the early days of our friendship. Once again, we were walking (and working) together in the nature. One time the three of us took a shortcut on the way back to the hotel - but the intensive discussions made sure that we didn't arrive any earlier. The plan to hold a joint conference in Tomsk was born and we made plans to try to organize this conference thematically and chronologically.

Unfortunately, these plans could not be realized because Sergei Psakhie left us suddenly and completely unexpectedly in December 2018. This was a great shock for all of us.

I am very glad that I can contribute to the memory of the great scientist and man Sergei Psakhie by co-editing this monograph and co-organizing the commemorative workshop on "Multiscale Biomechanics and Tribology of Inorganic and Organic 
Systems" in Tomsk in October 2019. My wife and I experienced and got to know Tomsk, the home city of Sergey, up close for the first time. We visited his place of work, and also the nature around Tomsk, with the feeling that he was still very much with us.

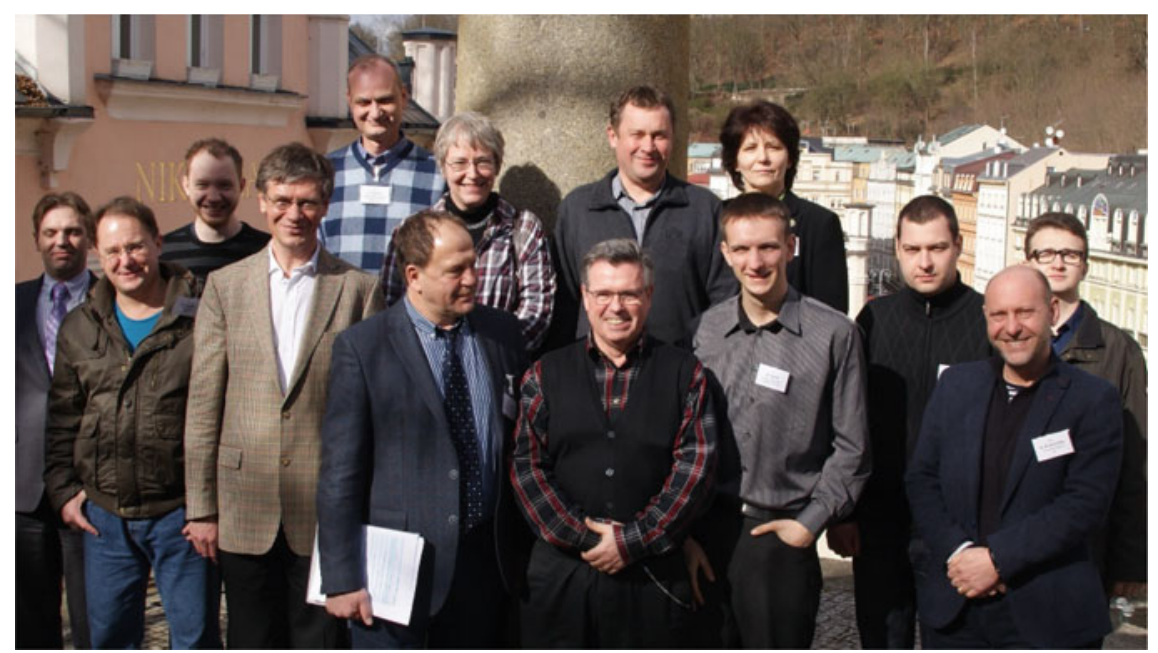

At the German-Russian Workshop "Advances in Tribology: Science, Technology and Education", Karlovy Vary, Czech Republic, March 2, 2015. First row left: S. G Psakhie, rigth: G. P. Ostermeyer, behind them: Ulrike Ketterl-Ostermeyer. Other participants (from the left): E. Shilko, V. Aleshin, M. Popov, V. Popov, A. Smolin, A. Dmitriev, R. Pohrt, J. Starcevic, E. Kolubaev, A. Korsunsky, A. Dimaki

\section{Valentin L. Popov: A Word of Sergey Psakhie}

V. L. Popov is the head of Department of System Dynamics and Friction Physics at the Technische Universität Berlin.

My collaboration and close friendship with Sergey Grigorievich Psakhie started in 1997. Together with Prof. E. Santner, at that time the head of tribology department of the Federal Institute of Materials Research and Testing (BAM), we submitted a joint project devoted to simulation of tribological processes with the Method of Movable Cellular Automaton. This project became a great success and established for many years one of research directions at the BAM.

Sergey Psakhie was the most important partner of the Department of System Dynamics and Friction Physics of Technische Universität Berlin, which I headed since 2002. Our cooperation covered diverse areas to which tribology can be applied: molecular motors and earth tectonics, problems of material wear and damping of aerospace structures, active control of friction and, of course, numerical modeling methods in tribology. Most important for us was scientific collaboration in the field of 
application of mesoparticle approach, in particular Cellular Automata, to tribological problems. Among a large number of papers, I can highlight our very fundamental and highly cited programmatic joint paper, "Numerical Simulation Methods in Tribology", appeared in 2007, which contained the most important future developments in this field such as Method of Dimensionality Reduction, applications of MCA and stochastic differential equations.

The forms of cooperation were correspondingly manifold: annual GermanRussian workshops (in fact international conferences), seismological field expeditions, multiple joint projects, invited professorships, international laboratories, visits of student groups, academic exchanges and finally the Double Degree Program with the Polytechnic University initiated by Prof. Psakhie in 2006. The program ran on the base of the Department of High Technology Physics in Mechanical Engineering headed by Sergey Psakhie. Since that time, about 100 German students studied in Tomsk thanks to these programs.

Sergey Psakhie was director of an academic institute. And he suited this position very well. He was a surprisingly harmonious and versatile person. Despite the fact that he devoted his life to materials, he was always attracted to biological topics. He believed that the twenty-first century is the century of biology, especially molecular biology. He was an expert in both fields. And not just an expert. He was a visionary, theorist and practitioner in one. Sergey Psakhie was a very erudite and well-read man. My wife Elena, a philologist with a double education (graduated from the Tomsk State University in Russian philology and from Paderborn University in German philology) had many times to urgently re-read works, heroes or conflicts of which Sergey mentioned.

In October of 2018, Sergey Psakhie and I, together with the rector of TSU, Eduard Vladimirovich Galazhinsky, discussed a new scientific direction - active biocontact mechanics, the purpose of which is the natural restoration of joints controlled by mechanical and medical means, instead of surgical replacement. Already in December 2018 the preparation of a joint multilateral project was in full swing. But when I received the sad news on Saturday morning, 22. December 2018, my thoughts were not about cooperation and not about laboratories. Because Sergey Psakhie was not only my colleague, but also a close friend of my whole family. The memory machine has started and cannot stop until now...

In 2005, we celebrated Christmas at the Baltic Sea, in Warnemünde. It is easy to imagine the weather in North Germany at the end of December. Nevertheless, Sergey jokingly suggested taking a swim next morning. Indeed, at 6.00 am in the morning, still in the dark, my sons, Nikita and Misha woke him up and pulled him to go swimming. There is a historical photograph capturing Sergey Psakhie with Nikita and Misha swimming in fur hats in the Baltic Sea on the 25th of December.

We often took vacations together and Sergey supplied us with ideas for movies to watch. One of these movies was "The Discreet Charm of the Bourgeoisie" by Luis Bunuel, which we watched many times.

Like many parents, I sometimes suffer from a critical attitude towards my children. Sergey constantly corrected me and told me how talented they are and what they fascinate him with. 
Sergey introduced Russia to my German colleagues. I would like to mention just two names: Jasminka Starcevic, who was a devoted close friend of Sergey Psakhie; and, of course, Professor Ostermeyer with his wife Ulrike, with whom Sergey Psakhie had a family friendship.

Sergey Psakhie was a true friend who we regard as a member of our family. He entered our lives a long time ago and will remain in them forever.

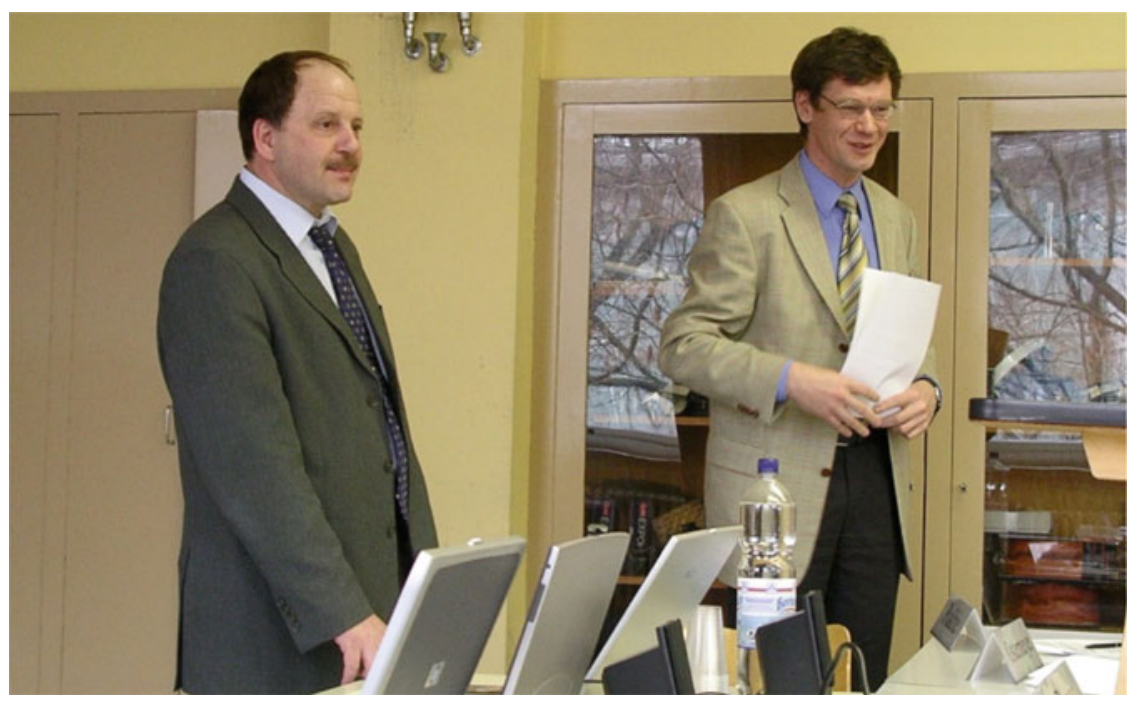

Sergey Psakhie and Valentin Popov at the German-Russian Workshop on "Numerical simulation methods in tribology: possibilities and limitations" (Technische Universität Berlin, March 2005)

\section{Lev B. Zuev: From My Memories of Sergey G. Psakhie}

L. B. Zuev is the head of Laboratory of Strength Physics at the Institute of Strength Physics and Materials Science, SB RAS.

I met Sergey Grigorievich Psakhie in 1983. At that time, I headed the Department of Physics at the Siberian Metallurgical Institute in Novokuznetsk, but my moving to the Institute of Strength Physics and Materials Science in Tomsk (which had just formed) was under discussion. The future director of the institute, V. E. Panin, invited me to participate in a Session of the Scientific Council of the USSR Academy of Sciences on strength and ductility. The session was held in a pioneer camp in the village of Zavarzino, located close to the Tomsk Academic Township. Sergey Psakhie was responsible for organization of this Session. It was the fall of 1983 - four months before the official opening of the Institute. 
I worked with Sergey Psakhie as his deputy for ten years, from 2002 to 2012. In these years, on his initiative, the research topics and the structure of the Institute have been substantially modernized. New laboratories and new research areas opened, often quite distant from the physics of strength, but ideally fitting into materials science in a broader sense. The technological base of the Institute has been significantly expanded and improved. This allowed rapid progress in our research at the highest international level.

I liked the style of the meetings Sergey Psakhie ran at the Institute. They were relatively brief. He usually listened to a number of points of view, which were presented by the participants, and then quickly made a decision. I want to note that the decision was made at the right time, not too early, and not too late. This contributed to the formation of an optimal point of view, but excluded a long debate that almost never leads to a useful result.

It seems important to me that Sergey Psakhie had a sense of what is now called "growth points", an ability to notice teams and people who have the potential for growth and development. He always considered it his duty to promote their development, which, in turn, contributed to the progress of the Institute as a whole.

I think that even organizational work gave Sergey Psakhie pleasure. He clearly sought to concentrate in his hands the work on opening new areas of research, networking, negotiations, making key decisions, choosing partners, etc.

I was twelve years older than Sergey Psakhie, and with such a difference in age we have not been friends. However, closer, what is called "human" contacts with him developed due to my health problems. His enormous decisive help in this respect did not belong to the scope of duties of director. When a medical treatment was necessary, he immediately picked up the phone, called medical doctors he knew, and even accompanied me to the hospital, which was not necessary at all. Sergey Psakhie considered such help a person's duty.

I am thankful to Sergey Psakhie for a lot, and especially for the editing of my book "Autowave plasticity. Localization and collective modes", which was published in 2018. He proposed the concise title of this monograph and wrote a short introduction to it. I still managed to present him a copy of the book...

I think that Sergey Psakhie was a man of integrity, and such people are always complex. Nevertheless, I am happy that I had the opportunity to work with him for a long time... 


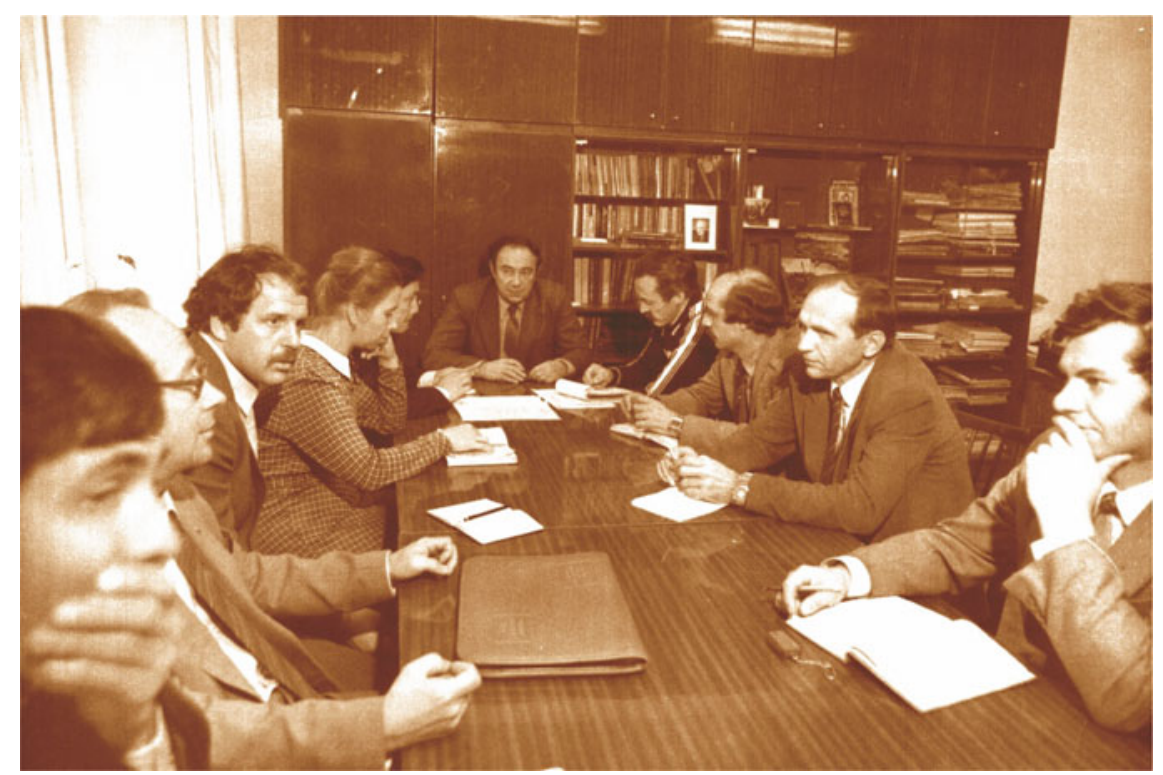

Meeting of the director board of ISPMS SB RAS (ca. 1985). Third from the left: S. G. Psakhie, second from the left L. B. Zuev. The meeting is chaired by the founder and first director of ISPMS SB RAS, V.E. Panin

\section{Valery V. Ruzhich: On the "Earthquake Vaccine" Project of Sergey Psakhie}

V. V. Ruzhich is the Principal Researcher of the laboratorium of Sesimology at the Institute of Earth's Crust, SB RAS, Irkutsk.

The eternal question of how to reduce the destructive consequences of strong earthquakes remains unresolved for many thousands of years. Humanity does not have means to affect the energetics of the deep tectonic processes leading to earthquakes. However, it is legitimate to pose the question: is it possible to find ways to reduce, disperse, or "streamline" the rampant play of the underground elements, manifested in the form of seismo-tectonic catastrophes? This issue was at the center of the project that emerged in the late 1990s and was realized under guidance of Sergey Psakhie. Journalists called the methods developed in the framework of this project "vaccination" from earthquakes.

Our first meeting with Sergey Psakhie took place in 1999 at the initiative of Academician Sergei Vasilievich Goldin at one of the interdisciplinary seminars. The ambitious idea of creating methods of controlled technogenic impacts on faults to mitigate and dissipate the destructive energy stored in the crust interested Sergey Psakhie, although it was very far from the subject of his main research. He belonged 
to a rare category of researchers with a huge arsenal of knowledge and own scientific developments, but at the same time very sensitive to innovation. He initiated a project with participation of specialists from 7 scientific organizations of the Russian Federation and Technische Universität Berlin. By 2003, at the Listvyanka landfill in the Angarsk seismically active fault zone, wells were drilled, strain and seismic regime monitoring was organized, and the seismic zone was modeled theoretically. In August 2004, original field experiments were conducted on a real seismic hazardous fault with vibrations, shocks and explosions in combination with injecting water solutions through wells into particular fault fragments. With this complex action, it was possible to induce an accelerated creep mode and to shift the fault banks on the length of about $100 \mathrm{~m}$ by $8-10 \mathrm{~mm}$. In 2006, these unique results were recognized by the Siberian Branch of the Russian Academy of Sciences as a breakthrough in seismic research. In the same year, the authors obtained the patent of the Russian Federation "A method for controlling the displacement mode in fragments of seismically active tectonic faults".

Ice chronicle on Baikal. In 2005 Sergey Psakhie proposed a unique scientific project to study the conditions of deformation and dynamic fracture of the ice cover of Lake Baikal, related to the seismically active Baikal rift basin. Annually, many kilometers long main cracks occur in the ice cover, which are accompanied by dynamic phenomena called ice impacts - registered in the form of seismic tremors with an energy comparable to weak tectonic earthquakes. It was assumed that their study might facilitate understanding of similar processers in the lithosphere. An interdisciplinary team of researchers from several scientific institutions, under the guidance of Sergey Psakhie, collected information that contributed to improvement of methods for controlling the regimes of seismic emission generation.

Our last meeting with Sergey Psakhie took place in Tomsk in the fall of 2018, during the annual international conference. With his extensive scientific and organizational activities, Sergey subjected his health to extreme loads, reaching far beyond the functions of the director of a research institute. His regular trips to Moscow and Novosibirsk for solving numerous organizational and funding issues did not leave him any time for recreation. At our last lunch in the cafe of the Academic Township in Tomsk, we discussed the plan for a joint winter expedition in 2019 on the ice of Lake Baikal. When parting, I asked him about his health-he looked tired, but habitually lively. Sitting behind the steering wheel of his SUV, he cheerfully replied: "Fine, only the left lower leg aches a little..."

Two months later, on the day of my birth, friends from Tomsk sent a deafeningly deplorable message about the sudden tragic departure of Sergey Grigorievich Psakhie...

As a tribute of deep respect and in memory of Sergey Psakhie, it is necessary for all of us, his friends and followers to continue research on improving the "vaccine" that is in great demand by the international community against imminent seismic disasters. 


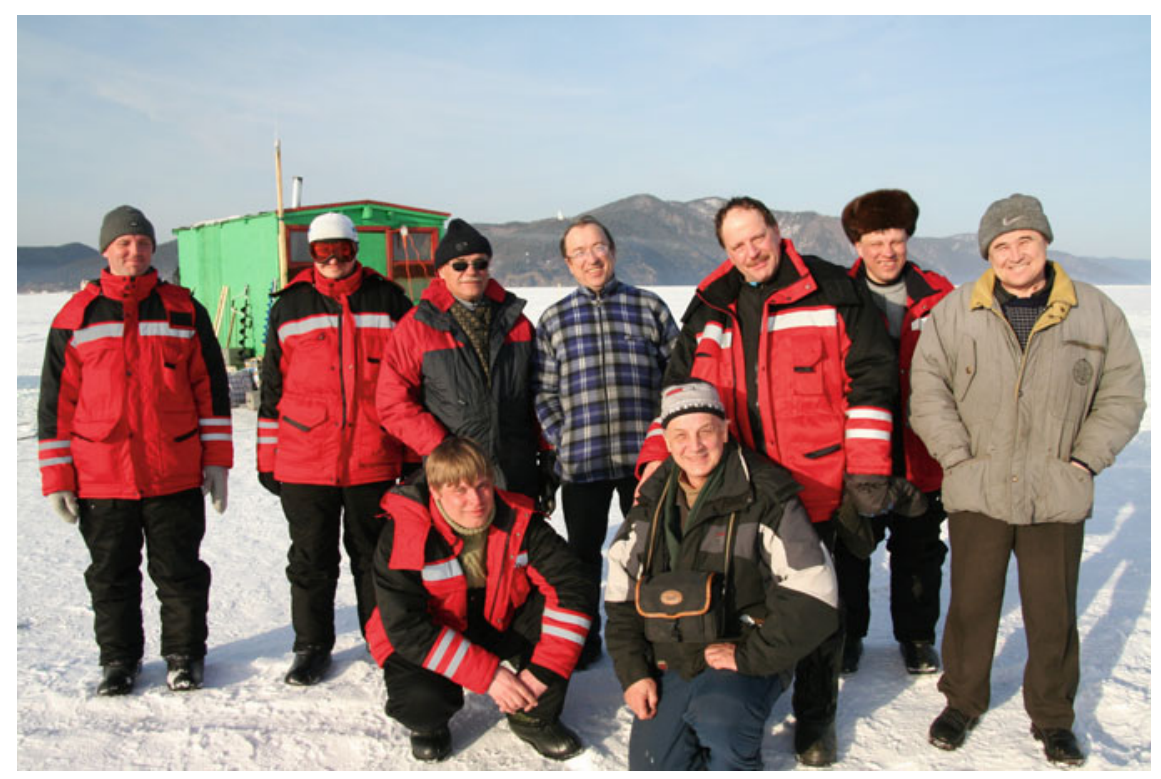

On the ice of Lake Baikal. Prof. Ruzhich is the right in the front row. Prof. Psakhie is behind him

\section{Most Important Publications of Prof. Sergey Grigorievich Psakhie}

\section{Particle-based and continuum approaches to computational modeling of materials}

Development of particle-based and continuum approaches to computational modeling of the mechanical behavior of materials under complex loading conditions.

1. Grigoriev, A. S., Shilko, E. V., Skripnyak, V. A., Psakhie, S. G. (2019). Kinetic approach to the development of computational dynamic models for brittle solids, International Journal of Impact Engineering, 123, 4-25.

2. Grinyaev, Yu. V., Chertova, N. V., Shilko, E. V., Psakhie, S. G. (2018). The continuum approach to the description of semi-crystalline polymers deformation regimes: the role of dynamic and translational defects, Polymers, 10, 1155 .

3. Psakhie, S. G., Dimaki, A. V., Shilko, E. V., Astafurov, S. V. (2016). A coupled discrete element-finite difference approach for modeling mechanical response of fluid-saturated porous materials, International Journal for Numerical Methods in Engineering, 106, 623-643.

4. Shilko, E. V., Psakhie, S. G., Schmauder, S., Popov, V. L., Astafurov, S. V., Smolin, A. Yu. (2015). Overcoming the limitations of distinct element method 
for multiscale modeling of materials with multimodal internal structure, Computational Materials Science, 102, 267-285.

5. Psakhie, S. G., Shilko, E. V., Grigoriev, A. S., Astafurov, S. V., Dimaki, A. V., Smolin, A. Yu. (2014). A mathematical model of particle-particle interaction for discrete element based modeling of deformation and fracture of heterogeneous elastic-plastic materials, Engineering Fracture Mechanics, 130, 96-115.

6. Psakhie, S. G., Shilko, E. V., Smolin, A. Yu., Dimaki, A. V., Dmitriev, A. I., Konovalenko, Ig. S., Astafurov, S. V., Zavsek, S. (2011). Approach to simulation of deformation and fracture of hierarchically organized heterogeneous media, including contrast media, Physical Mesomechanics, 14, 224-248.

7. Grinyaev, Yu. V., Psakhie, S. G., Chertova, N. V. (2008). Phase space of solids under deformation, Physical Mesomechanics, 11, 228-232.

8. Psakhie, S. G., Smolin, A. Yu., Stefanov, Yu. P., Makarov, P. V., Chertov, M. A. (2004). Modeling the behavior of complex media by jointly using discrete and continuum approaches, Technical Physics Letters, 30, 712-714.

9. Psakhie, S. G., Horie Y., Ostermeyer G.-P., Korostelev, S. Yu., Smolin, A. Yu., Shilko, E. V., Dmitriev, A. I., Blatnik, S., Spegel, M., Zavsek, S. (2001). Movable cellular automata method for simulating materials with mesostructured, Theoretical and Applied Fracture Mechanics, 37, 311-334.

10. Popov, V. L., Psakhie, S. G. (2001). Theoretical principles of modeling elastoplastic media by movable cellular automata method. I. Homogeneous media, Physical Mesomechanics, 4, 15-25.

11. Psakhie, S. G., Horie, Y., Korostelev, S. Yu., Smolin, A. Yu., Dmitriev, A. I., Shilko, E. V., Alekseev, S. V. (1995). Method of movable cellular automata as a tool for simulation within the framework of mesomechanics, Russian Physics Journal, 38, 1157-1168.

II. Contact interaction, friction and wear

1. Dimaki, A. V., Dudkin, I. V., Shilko, E. V., Psakhie, S. G., Popov, V. L. (2020). Role of Adhesion Stress in Controlling Transition between Plastic, Grinding and Breakaway Regimes of Adhesive Wear, Scientific Reports, 10, 1585.

2. Willert, E., Dmitriev, A. I., Psakhie, S. G., Popov, V. L. (2019). Effect of elastic grading on fretting wear, Scientific Reports, 9, 7791.

3. Popov, V. L., Dimaki, A. V., Psakhie, S. G., Popov, M. V. (2015). On the role of scales in contact mechanics and friction between elastomers and randomly rough self-affine surfaces, Scientific Reports, 5, 11139.

4. Li, Q., Dimaki, A., Popov, M., Psakhie, S. G., Popov, V. L. (2014). Kinetics of the coefficient of friction of elastomers, Scientific Reports, 4, 5795.

5. Psakhie, S. G., Popov, V. L., Shilko, E. V., Smolin, A. Yu., Dmitriev, A. I. (2009). Spectral analysis of the behavior and properties of solid surface layers. Nanotribospectroscopy, Physical Mesomechanics, 12, 221-234.

6. Popov, V. L., Psakhie, S. G. (2007). Numerical simulation methods in tribology, Tribology International, 40, 916-923. 
7. Bucher, F., Dmitriev, A. I., Ertz, M., Knothe, K., Popov, V. L., Psakhie, S. G., Shilko, E. V. (2006). Multiscale simulation of dry friction in wheel/rail contact, Wear, 261, 874-884.

8. Popov, V. L., Psakhie, S. G., Dmitriev, A. I., Shilko, E. V. (2003). Quasi-fluid nano-layers at the interface between rubbing bodies: simulations by movable cellular automata, Wear, 254, 901-906.

9. Popov, V. L., Psakhie, S. G., Shilko, E. V., Dmitriev, A. I., Knothe, K., Bucher, F., Ertz, M. (2002). Friction coefficient in "rail-wheel" contacts as a function of material and loading parameters, Physical Mesomechanics, 5(3-4), 17-24.

III. Seismic activity of geological media and controlling displacement modes in fault zones

1. Shilko, E. V., Dimaki, A. V., Psakhie, S. G. (2018). Strength of shear bands in fluid-saturated rocks: a nonlinear effect of competition between dilation and fluid flow, Scientific Reports, 8, 1428.

2. Ruzhich, V. V., Psakhie, S. G., Chernykh, E. N., Shilko, E. V., Levina, E. A., Dimaki, A. V. (2018). Baikal ice cover as a representative block medium for research in lithospheric geodynamics, Physical Mesomechanics, 21, 223-233.

3. Grigoriev, A. S., Shilko, E. V., Astafurov, S. V., Dimaki, A. V., Vysotsky, E. M., Psakhie, S. G. (2016). Effect of dynamic stress state perturbation on irreversible strain accumulation at interfaces in block-structured media, Physical Mesomechanics, 19, 136-148.

4. Psakhie, S. G., Dobretsov, N. L., Shilko, E. V., Astafurov, S. V., Dimaki, A. V., Ruzhich, V. V. (2009). Model study of the formation of deformation-induced structures of subduction type in block-structured media. Ice cover of Lake Baikal as a model medium, Tectonophysics, 465, 204-211.

5. Psakhie, S. G., Shilko, E. V., Astafurov, S. V., Dimaki, A. V., Ruzhich, V. V., Panchenko, A. Yu. (2008). Model study of the formation and evolution of deformation induced structures of the subduction type in the ice cover of Lake Baikal, Physical Mesomechanics, 11, 55-65.

6. Psakhie, S. G., Ruzhich, V. V., Shilko, E. V., Popov, V. L., Astafurov, S. V. (2007). A new way to manage displacements in zones of active faults, Tribology International, 40, 995-1003.

7. Dobretsov, N. L., Psakhie, S. G., Ruzhich, V. V., Popov, V. L., Shilko, E. V., Granin, N. G., Timofeev, V. Yu., Astafurov, S. V., Dimaki, A. V., Starcevic, Ya. (2007). Ice cover of Lake Baikal as a model for studying tectonic processes in the Earth's crust, Doklady Earth Sciences, 413, 155-159.

8. Psakhie, S. G., Ruzhich, V. V., Shilko, E. V., Popov, V. L., Dimaki, A. V., Astafurov, S. V., Lopatin, V. V. (2005). Influence of the state of interfaces on the character of local displacements in fault-block and interfacial media, Technical Physics Letters, 31, 712-715.

9. Psakhie, S. G., Ruzhich, V. V., Smekalin, O. P., Shilko, E. V. (2001). Response of the geological media to dynamic loading, Physical Mesomechanics, 4(1), 63-66.

\section{Vortices as a fundamental mechanism of material response to loading}


1. Shilko, E. V., Astafurov, S. V., Grigoriev, A. S., Smolin, A. Yu., Psakhie, S. G. (2018). The fundamental regularities of the evolution of elastic vortices generated in the surface layers of solids under tangential contact loading, Lubricants, 6,51 .

2. Shilko, E. V., Grinyaev, Yu. V., Popov, M. V., Popov, V. L., Psakhie, S. G. (2016). Nonlinear effect of elastic vortexlike motion on the dynamic stress state of solids, Physical Review. E, 93, 053005.

3. Psakhie, S. G., Shilko, E. V., Popov, M. V., Popov, V. L. (2015). The key role of elastic vortices in the initiation of intersonic shear cracks, Physical Review. E, 91, 063302.

4. Psakhie, S. G., Zolnikov, K. P., Dmitriev, A. I., Smolin, A. Yu., Shilko, E. V. (2014). Dynamic vortex defects in deformed material, Physical Mesomechanics, 17, 15-22.

5. Psakhie, S. G., Smolin, A. Yu., Shilko, E. V., Korostelev, S. Yu., Dmitriev, A. I., Alekseev, S. V. (1997). About the features of transient to steady state deformation of solids, Journal of Materials Science and Technology, 13, 69-72.

6. Psakhie, S. G., Smolin, A. Yu., Korostelev, S. Yu., Dmitriev, A. I., Shilko, E. V., Alekseev, S. V. (1995). The study of establishing the steady mode of deformation of solids by the method of movable cellular automata, Pis'ma Zh. Tech. Phys, 21(20), 72.

V. Atomic mechanisms of inelastic deformation of crystalline solids

1. Psakhie, S. G., Zolnikov, K. P., Kryzhevich, D. S., Korchuganov, A. V. (2019). Key role of excess atomic volume in structural rearrangements at the front of moving partial dislocations in copper nanocrystals, Scientific Reports, 9, 3867.

2. Korchuganov, A. V., Tyumentsev, A. N., Zolnikov, K. P., Litovchenko, I. Yu., Kryzhevich, D. S., Gutmanas, E., Li, S. X., Wang, Z. G., Psakhie, S. G. (2019). Nucleation of dislocations and twins in fcc nanocrystals: Dynamics of structural transformations, Journal of Materials Science and Technology, 35, 201-206.

3. Zolnikov, K. P., Korchuganov, A. V., Kryzhevich, D. S., Chernov, V. M., Psakhie, S. G. (2019). Formation of Point Defect Clusters in Metals with Grain Boundaries under Irradiation, Physical Mesomechanics, 22(5), 355-364.

4. Korchuganov, A. V., Zolnikov, K. P., Kryzhevich, D. S., Psakhie, S. G. (2017). Primary Ion-Irradiation Damage of BCC-Iron Surfaces, Russian Physics Journal, 60, 170-174.

5. Korchuganov, A. V., Zolnikov, K. P., Kryzhevich, D. S., Chernov, V. M., Psakhie, S. G. (2016). MD simulation of plastic deformation nucleation in stressed crystallites under irradiation, Physics of Atomic Nuclei, 79(7), 1193-1198.

6. Zolnikov, K. P., Korchuganov, A. V., Kryzhevich, D. S., Chernov, V. M., Psakhie, S. G. (2015). Structural changes in elastically stressed crystallites under irradiation, Nuclear Instruments \& Methods in Physics Research Section B-Beam Interactions with Materials and Atoms, 352, 43-46. 
7. Dmitriev, A. I., Nikonov, A. Yu., Psakhie, S. G. (2011). Atomistic mechanism of grain boundary sliding with the example of a large-angle boundary $2=5$. Molecular dynamics calculation, Physical Mesomechanics, 14, 24-31.

8. Psakhie, S. G., Zolnikov, K. P., Dmitriev, A. I., Konovalenko, Iv. S. (2009). Kinematic properties of nanostructures based on bilayer nanocrystalline films, Physical Mesomechanics, 12, 112-116.

9. Psakhie, S. G., Zolnikov, K. P., Kryzhevich, D. S. (2007). Elementary atomistic mechanism of crystal plasticity, Physics Letters A, 367, 250-253.

10. Psakhie, S. G., Zolnikov, K. P., Kryzhevich, D. S., Lipnitskii, A. G. (2006). On structural defect generation induced by thermal fluctuations in materials with a perfect lattice under dynamic loading, Physics Letters A, 349, 509-512.

11. Psakhie, S. G., Zolnikov, K. P. (1998). Possibility of a vortex mechanism of displacement of the grain boundaries under high-rate shear loading, Combustion Explosion and Shock Waves, 34(3), 366-368.

12. Psakhie, S. G., Zolnikov, K. P. (1997). Anomalously high rate of grain boundary displacement under fast shear loading, Technical Physics Letters, 23, 555-556.

13. Psakhie, S. G., Korostelev, S. Y., Negreskul, S. I., Zolnikov, K. P., Wang, Z. G., Li, S. X. (1993). Vortex mechanism of plastic-deformation of grainboundaries-computer-simulation, Physica Status Solidi B-Basic research, 176(2), K41-K44

14. Zolnikov, K. P., Psakhie, S. G., Panin, V. E. (1986). Alloy phase-diagrams using temperature, concentration and density as variables, Journal of Physics F-Metal Physics, 16, 1145-1152.

15. Psakhie, S. G., Panin, V. E., Chulkov, E. V., Zhorovkov, M. F. (1980). Pseudopotential theory calculation of bounding energy of zinc atom with vacancy in aluminum, Fizika Metallov i Metallovedenie, 50, 620-622.

16. Psakhie, S. G., Panin, V. E., Chulkov, E. V., Zhorovkov, M. F. (1980). Calculation of the bond-energy of $\mathrm{Mg}$ and $\mathrm{Zn}$ impurities with vacancies in Al-alloys, Izvestiya Vysshikh Uchebnykh Zavedenii Fizika, 8, 99-104.

\section{Biological and medical applications}

1. Sharipova, A., Gotman, I., Psakhie, S. G., Gutmanas, E. Y. (2019). Biodegradable nanocomposite Fe-Ag load-bearing scaffolds for bone healing, Journal of the Mechanical Behavior of Biomedical Materials, 98, 246-254.

2. Lerner, M. I., Mikhaylov, G., Tsukanov, A. A., Lozhkomoev, A. S., Gutmanas, E., Gotman, I., Bratovs, A., Turk, V., Turk, B., Psakhie, S. G., Vasiljeva, O. (2018). Crumpled aluminum hydroxide nanostructures as a microenvironment dysregulation agent for cancer treatment, Nano Letters, 18, 5401-5410.

3. Sharipova, A., Swain, S. K., Gotman, I., Starosvetsky, D., Psakhie, S. G., Unger, R., Gutmanas, E. Y. (2018). Mechanical, degradation and drug-release behavior of nano-grained Fe-Ag composites for biomedical applications, Journal of the Mechanical Behavior of Biomedical Materials, 86, 240-249.

4. Tsukanov, A. A., Psakhie, S. G. (2017). From the soft matter-hard matter interface to bio-self-organization and hybrid systems, Physical Mesomechanics, 20, 43-54. 
5. Tsukanov, A. A., Psakhie, S. G. (2016). Energy and structure of bonds in the interaction of organic anions with layered double hydroxide nanosheets: A molecular dynamics study, Scientific Reports, 6, 19986.

6. Lozhkomoev, A. S., Glazkova, E. A., Bakina, O. V., Lerner, M. I., Gotman, I., Gutmanas, E. Y., Kazantsev, S. O., Psakhie, S. G. (2016). Synthesis of coreshell $\mathrm{AlOOH}$ hollow nanospheres by reacting Al nanoparticles with water, Nanotechnology, 27, 205603.

7. Bakina, O. V., Glazkova, E. A., Svarovskaya, N. V., Lozhkomoev, A. S., Lerner, M. I., Psakhie, S. G. (2015). The influence of precursor disaggregation during synthesis of low-dimensional AlOOH structures on their morphology, Russian Physics Journal, 57, 1669-1675.

8. Mishnaevsky, L. Jr., Levashov, E., Valiev, R. Z., Segurado, J., Sabirov, I., Enikeev, N., Prokoshkin, S., Solov'yov, A. V., Korotitskiy, A., Gutmanas, E., Gotman, I., Rabkin, E., Psakhie, S. G., Dluhoš, L., Seefeldt, M., Smolin, A. (2014). Nanostructured titanium-based materials for medical implants: Modeling and development, Materials Science and Engineering: R: Reports, 81, 1-19.

9. Mikhaylov, G., Mikac, U., Magaeva, A. A., Itin, V. I., Naiden, E. P., Psakhye, I., Babes, L., Reinheckel, T., Peters, C., Zeiser, R., Bogyo, M., Turk, V., Psakhie, S. G., Turk, B., Vasiljeva, O. (2011). Ferri-liposomes as an MRI-visible drugdelivery system for targeting tumours and their microenvironment, Nature Nanotechnology, 6, 594-602.

VII. Dusty plasma as a special state of particulate matter

1. Psakhie, S. G., Zolnikov, K. P., Abdrashitov, A. V. (2010). On the formation of structural states in dusty plasmas \& Physical Mesomechanics, 13(5-6), 275-282.

2. Abdrashitov, A. V., Zolnikov, K. P., Psakhie, S. G. (2010). Effect of the Anisotropy of Confining Field on the Structure of Dusty Plasma Clusters, Technical Physics Letters, 36(10), 910-913.

3. Psakhie, S. G., Zolnikov, K. P., Abdrashitov, A. V. (2009). Studying the response of a Coulomb ball of charged dust particles to external pulsed loads \&Technical Physics Letters, 35(2), 120-122.

4. Psakhie, S. G., Zolnikov, K. P., Skorentsev, L. F., Kryzhevich, D. S., Abdrashitov, A. V. (2008). Structural features of bicomponent dust Coulomb balls formed by the superposition of fields of different origin in plasma, Physics of Plasmas, 15, 053701.

5. Psakhie, S. G., Zolnikov, K. P. (2008). Structure of binary dust Coulomb balls in confining fields of different origin, Physical Mesomechanics, 11(3-4), 144-148.

6. Psakhie, S. G., Zolnikov, K. P., Skorentsev, L. F., Kryzhevich, D. S., Abdrashitov, A. V. (2008). Structural features of two-component dusty plasma Coulomb balls, Technical Physics Letters, 34(4), 319-322. 
Open Access This chapter is licensed under the terms of the Creative Commons Attribution 4.0 International License (http://creativecommons.org/licenses/by/4.0/), which permits use, sharing, adaptation, distribution and reproduction in any medium or format, as long as you give appropriate credit to the original author(s) and the source, provide a link to the Creative Commons license and indicate if changes were made.

The images or other third party material in this chapter are included in the chapter's Creative Commons license, unless indicated otherwise in a credit line to the material. If material is not included in the chapter's Creative Commons license and your intended use is not permitted by statutory regulation or exceeds the permitted use, you will need to obtain permission directly from the copyright holder.

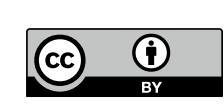

